\title{
Coroas Endoncrown: uma revisão de literatura e relato de caso
}

\author{
Endoncrown Crowns: a literature review and case report \\ Coronas Endoncrown: una revisión de literatura y relato de caso

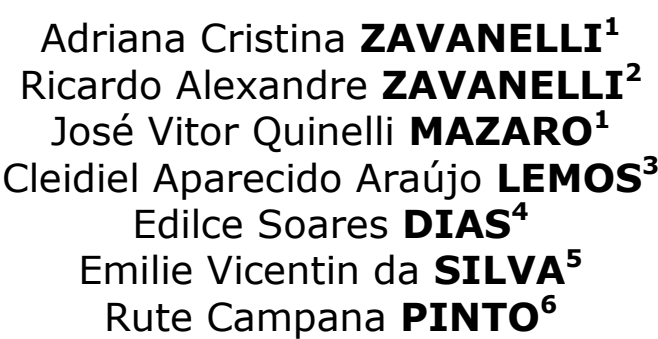 \\ ${ }^{I}$ Departamento de Materiais Odontológicos e Prótese da Faculdade de Odontologia de Araçatuba, \\ Universidade Estadual Paulista "Júlio de Mesquita Filho", UNESP. \\ ${ }^{2}$ Departamento de Prevenção e Reabilitação Oral da Faculdade de Odontologia da Universidade Federal de Goiás, UFG \\ ${ }^{3}$ Doutorando em Prótese Dentária pela Faculdade de Odontologia de Araçatuba, \\ Universidade Estadual Paulista "Júlio de Mesquita Filho",UNESP. \\ ${ }^{4}$ Especialista em Prótese Dentária - IKO. \\ ${ }^{5}$ Cirurgiã-Dentista, Faculdade de Odontologia de Araçatuba, \\ Universidade Estadual Paulista "Júlio de Mesquita Filho",UNESP \\ ${ }^{6}$ Especialista em Prótese Dentária - NEC Odonto, Araçatuba-SP, Brasil
}

\section{Resumo}

Dentes tratados endodonticamente possuem redução da rigidez e resistência devido à perda da integridade estrutural. Este fato pode acarretar em longo prazo falhas biomecânicas, falta de elasticidade e de resistência à tração frente às forças mastigatórias, não sendo incomum que problemas mais graves como fraturas ocorram. Logo, a escolha da reabilitação funcional e estética desse paciente deve ser selecionada com muita cautela, já que a longevidade do tratamento endodôntico pode ser influenciada pela seleção do material restaurador, assim como do preparo protético do remanescente que conserve o máximo de estrutura dentária sadia. Este trabalho teve como objetivo apresentar uma revisão da literatura sobre o tema endocrown e ilustrar sua execução com caso clínico. O caso clínico evidenciou que a técnica endocrown está indicada para dentes posteriores, principalmente molares, que apresentem coroa clínica curta e espaço interoclusal insuficiente e estar associada às cerâmicas adesivas. Trata-se de um procedimento que visa à preservação da estrutura dental e resultados estéticos harmoniosos, além de executado em menos sessões clínicas. A literatura apoia que em comparação as tradicionais coroas totais, a resistência à fratura apresenta-se superior. É importante salientar que o sucesso clínico traduzido por longevidade e conforto é dependente do correto preparo e do uso das cerâmicas adesivas.

Descritores: Prótese Dentária; Prótese Parcial Fixa; Dente Molar; Dente não Vital.

\begin{abstract}
Endodontically treated teeth have reduced rigidity and resistance due to loss of structural integrity. This fact can result in long-term problems of biomechanical failure, lack of elasticity and traction resistance of masticatory forces, it is not uncommon for more serious problems such as fractures occur. Therefore, the choice of functional and esthetic rehabilitation of these patients should be selected with caution, since the longevity of the endodontic treatment can be influenced by selection of the restorative material and a preparation that conserve as much healthy tooth structure. Thus, the aim of this work was to present a brief review of literature about the subject endocrown and illustrate their performance with clinical case. This case showed that endocrown technique is indicated to posterior teeth, especially molars, which have short clinical crown and insufficient interocclusal space and be associated with adhesive ceramic. This is a procedure that aims at preserving tooth structure and harmonious esthetic results, in addiction to execute on less clinical sessions. The literature supports that compared to traditional crowns, the fracture resistance has to be superior. It is Important to note that the clinical success translated by longevity and comfort is dependent on the correct preparation and use of adhesive ceramic.

Descriptors: Dental Prosthesis; Denture, Partial, Fixed; Molar; Tooth, Nonvital.
\end{abstract}

\section{Resumen}

Los dientes tratados endodónticamente poseen una reducción de la rigidez y la resistencia debido a la pérdida de la integridad estructural. Este hecho puede acarrear a largo plazo problemas de fallas biomecánicas, falta de elasticidad y de resistencia a la tracción de fuerzas masticatorias, no siendo raro problemas más graves como fracturas. La elección de la rehabilitación funcional y estética de este paciente debe ser seleccionada con mucha cautela, ya que la longevidad del tratamiento endodóntico puede verse influenciada por la selección del material restaurador y también de una preparación que conserve el máximo de estructura dental sana. Este trabajo tiene como objetivo presentar una breve revisión de la literatura sobre el tema endocrown e ilustrar su ejecución con el caso clínico. El trabajo y lo caso clínico evidenció que la técnica endocrown está indicada para dientes posteriores, principalmente molares, que presenten corona clínica corta y espacio interoclusal insuficiente y estar asociada a las cerámicas adhesivas. Se trata de un procedimiento que apunta a la preservación de la estructura dental y resultados estéticos armoniosos, además de ejecutado en menos sesiones clínicas. La literatura apoya que en comparación con las tradicionales coronas totales, la resistencia a la fractura se presenta superior. Es importante señalar que el éxito clínico traducido por longevidad y confort es dependiente de la correcta preparación y del uso de las cerámicas adhesivas.

Descriptores: Prótesis Dental; Dentadura Parcial Fija; Diente Molar; Diente no Vital.

\section{INTRODUÇÃO}

A realização do tratamento endodôntico pode ser indicada em situações na qual a estrutura dentária sofreu alguma injúria, seja por meio de cáries, traumas, fraturas, e extrusão severa da estrutura dentária. Entretanto, o tratamento endodôntico pode causar desgaste na estrutura dentária, deixando-a mais frágil e susceptível a fratura ${ }^{1}$.
O risco de fraturas aumenta principalmente em situações nas quais após perda da estrutura coronária são necessárias a utilização de retentores intrarradiculares, como os núcleos metálicos fundidos ${ }^{2}$, uma vez que esse material após fundição do metal apresenta elevado módulo de elasticidade em relação a estrutura dentária ${ }^{3}$. Além disso, 
esses materiais apresentam desvantagens ocasionadas pela corrosão do metal, afetando assim a estética do tratamento reabilitador ${ }^{3,4}$

Diante desse cenário, tratamentos alternativos têm sido pesquisados, com o objetivo de otimizar os resultados clínicos permitindo maior longevidade ao tratamento restaurador. A técnica de Endocrown foi proposta por Mormann e colaboradores ${ }^{5}$ em 1998, para pacientes que apresentam dentes com perda total da estrutura coronária, sendo confeccionado uma coroa em monobloco (coroa mais retenção na região da câmara pulpar), cimentada através das técnicas adesivas do dente tratado endodonticamente sem utilizar os condutos radiculares.

Atualmente existem diversos estudos relatando a utilização de coroas endocrown com uma taxa de sobrevivência das restaurações, reduzindo os riscos de complicações uma vez que o preparo interno fica limitado à cavidade pulpar, não causando a desobturação dos condutos radiculares ${ }^{5-9}$

A indicação desta técnica é, para dentes severamente comprometidos, principalmente molares, com canais radiculares calcificados ou raízes muito finas, comprimento de coroa clínica inadequada e/ou espaço interoclusal insuficiente $^{6-10}$. Diante disso, esse trabalho teve como objetivo realizar revisão da literatura sobre as coroas endocrown, ilustrando sua execução com um caso clínico.

\section{REVISÃO DA LITERATURA}

Para a identificação dos estudos incluídos e selecionados para esta revisão, foi considerada uma estratégia de busca detalhada nas bases de dados PubMed/Medline e Scholar Google, sendo utilizados os descritores: "endocrown" e "coroas endocrown" verificando artigos publicados até janeiro de 2017. Os critérios de inclusão foram: artigos clínicos, estudos in vitro e/ou laboratoriais e revisões que abordassem o tema de coroas endocrown.

\section{Coroas Endocrown}

Em situações com coroas extensamente destruídas por muito tempo foram utilizados retentores intrarradiculares para a reabilitação, contudo, defeitos de funcionalidade através da prevalência de fraturas radiculares, ${ }^{9}$ e o problema estético ocasionado pela alteração de cor e/ou aparência acinzentada das restaurações são observadas com o passar do tempo. Diante disso, a razão de se desenvolver a técnica endocrown, que teve a sua primeira aplicação por volta de 1989 a 1992, variando a técnica de monobloco concluído com material de vitro-cerâmica.

Para que se tenha um prognóstico previsível e favorável na reabilitação em dentes com tratamento endodôntico, se faz necessário a presença de uma maior quantidade possível de dentina residual para que aumente a longevidade e força do elemento e da restauração ${ }^{11}$.

O padrão ouro para restauração do elemento dentário é a realização de preparos minimamente invasivos, visando preservar a maior quantidade de tecido dentário9. Além de proteger e preservar a estrutura dentária, as restaurações pós-tratamentos endodônticos devem aliar a isso a estética, forma anatômica e função satisfatórias, uma vez que a escolha do tipo de restauração depende da integridade estrutural do dente, estética e requisitos de proteção que melhore o prognóstico do elemento afetado ${ }^{7}$.

A opção mais tradicional até então de se recuperar a forma, função e estética dos dentes tratados endodonticamente com extensa perda coronal foi com coroas totais, que tem como indicações de seu uso quando há aumento de tensões evidenciando anatomia oclusal íngreme, facetas de desgaste ou parafunções ${ }^{8,9}$. Essas coroas totais podem ser suportadas por núcleos metálicos fundidos, garantindo retenção para a restauração. Complementa ainda que com a evolução dos materiais adesivos, como a resina composta, surgiram as opções de pinos pré-fabricados para reconstrução dentária em seção única não necessitando de etapas laboratoriais para fundição do retentor, além dessas estruturas apresentam propriedades físicas próximas ao da dentina, reduzindo ${ }^{9}$.

Em contrapartida, apesar das vantagens da utilização de pinos pré-fabricados, esse tipo de tratamento ainda continua tendo suas limitações devido à necessidade da retenção intrarradicular, podendo levar a uma perda de até $58,3 \%$ da estrutura dentária ${ }^{12}$. Além de aumentar o risco de complicações como a trepanação radicular durante o procedimento de desobturação do canal radicular, principalmente em dentes com alterações anatômicas radiculares $^{8,9,12}$ que é comum encontrar alterações anatômicas radiculares em molares, necessitando de manobras mais dificultosas no momento da desobturação, o que resulta em uma maior complexidade do tratamento caso a escolha seja utilizar o pino de fibra de vidro.

Com a evolução da odontologia adesiva surgiram materiais como adesivos dentinários, cimentos resinosos e cerâmicas ácidos sensíveis, proporcionando que o "design" macro retentivo, obtido pela reconstrução dentária após o uso de retentores, não seja mais um pré-requisito para o suporte da restauração cerâmica ${ }^{9}$. Estudos dizem que as técnicas adesivas visam uma abordagem mais conservadora, sem a necessidade de um preparo mais agressivo já que a adesão confere uma retenção suficiente do material, evitando perda de tecido dentinário sadio ${ }^{7,8,10}$.

Pensando nessas características de preservação e em casos em que há uma grande destruição coronal, surgiu a opção da técnica endocrown permitindo a restauração coronária através de retenção adesiva na câmara pulpar em dentes com a coroa comprometida, sem o uso de núcleo metálico ou pinos pré-fabricados. Segundo autores, ${ }^{6-10,12}$ as endocrowns podem ser classificadas como uma restauração indireta feita em monobloco cerâmico, ou seja, coroa e núcleo unidos, formando uma peça única com o mesmo material que terá uma retenção macro-mecânica no interior da câmara pulpar, promovendo estabilidade, juntamente com uma retenção micro mecânica através da cimentação com materiais adesivos.

A confecção desse tipo de peça protética é realizada através do sistema CAD-CAM, garantindo resultado de alta compatibilidade e ótimas propriedades mecânicas, permitindo que se devolva a estética e função para o paciente ${ }^{7}$. Entretanto, como já citado, é imprescindível um correto diagnóstico do caso e plano de tratamento para que o prognóstico seja o melhor possível, dessa forma, podemos indicar a restauração endocrown para casos de dentes tratados endodonticamente, ou seja, desvitalizados, dentes com integridade estrutural comprometida e extensa destruição coronária.

Segundo Biacchi et al. ${ }^{8}$, as coroas endocrowns são indicadas em situações que existam espaços interoclusais limitados, em que não é possível atingir a uma espessura suficiente de revestimento cerâmico no metal ou em situações de coroas clínicas curtas.

Em relação ao local do arco dentário onde a endocrown é mais indicada. Estudos ${ }^{6-10}$ apontam que esse tipo de coroa é mais indicada para dentes posteriores, principalmente molares, pois apresentam um desempenho 
satisfatório em relação às cargas fisiológicas, ou seja acredita-se que quanto maior a área estrutural da câmara pulpar, maior será o limite de resistência de união dos sistemas adesivos e cimentos resinosos. Além disso, a altura e largura do elemento dental também influenciam no aumento da resistência, sendo recomendado evitar ao máximo que seja realizado esse procedimento em dentes que tenham a necessidade de uma peça protética que apresenta sua altura maior que sua largura, pois isso poderia criar um braço de alavanca, aumentando o risco de ruptura e deslocamento, levando ao insucesso da restauração.

Devido a esses fatores, pode-se se explicar existe um maior cuidado na indicação desse tipo de tratamento para pré-molares. A anatomia de dentes pré-molares confere uma maior dificuldade de adesão, com sua cúspide sendo mais alta, há uma maior força exercida nele levando a um possível movimento de alavanca no elemento dental ${ }^{9}$. Da mesma forma, a indicação de endocrowns para incisivos pode ser comprometida devido à altura comparada com a largura, as forças mastigatórias aplicadas podem levar a um movimento de alavanca sobre o dente, resultando em uma possível fratura $^{12}$. A interface do dente no tamanho adequado para que uma endocrown funcione é muito importante, devido a isso, em molares cabe a melhor indicação, pois a sua interface é suficiente para que se evitem movimentos de alavanca.

Outras características importantes para indicação segundo Biacchi et al. ${ }^{8}$ especificamente nos casos dos molares, seriam em casos dos mesmos com raízes pequenas, obliteradas, dilaceradas ou frágeis, pois nesses casos seria ainda mais complexo o uso de um retentor intrarradicular associado a uma coroa total tradicional.

Os materiais de escolha para confecção da endocrown são as cerâmicas ácido-sensível como, por exemplo, o dissilicato de lítio reforçado por fibra, que dentro dessa classificação seria uma cerâmica mais resistente, e com o reforço das propriedades de absorção de tensões, manteria uma estética desejável ${ }^{7}$. Entretanto, Biacchi et al. ${ }^{8}$ relataram que o material de escolha mais adequado seria uma cerâmica ácido-resistente tal como a Zircônia, pois garante a resistência mecânica necessária e adequada para suportar as forças oclusais e de resistência entre restauração e paredes da cavidade. Dessa forma, não existe um consenso a respeito material mais indicado para essas situações.

Inúmeras são as vantagens para o uso da técnica endocrown como o restabelecimento estético e função, permitindo maior conservação de tecido dentinário e esmalte periférico em comparação a coroas totais convencionais ${ }^{6,13}$, visto que essa preservação de tecido promove maior estabilidade marginal.

Outro ponto importante seria em relação às margens da restauração que com essa técnica são mantidas fora da área do periodonto, sendo assim benéfico para conservação da higiene oral e saúde periodontal, uma vez que quando as margens são próximas ao espaço biológico, podem ocorrer reações indesejadas no periodonto justamente pela dificuldade da higienização ${ }^{14}$. Em relação aos passos técnicos, ele diz ainda que os mesmos sejam diminuídos em comparação aos passos de quando é realizada uma reabilitação com núcleo ou pino com coroas totais, portanto, menos sessões clínicas são requisitadas.

Segundo Carlos et al. ${ }^{7}$ em relação à confecção da peça protética, com a evolução dos sistemas cerâmicos e dos sistemas de confecção, temos vantagens de se obter uma fresagem mais precisa, com formato personalizado, adaptação da superfície interior da restauração e a replicação da morfologia oclusal melhores, as imprecisões e contaminação cruzada são mínimas, evita contração de polimerização por ser uma restauração indireta e se tem melhor adesão e satisfação do paciente.

Entretanto, apesar de todas as vantagens apresentadas essa técnica pode apresentar algumas limitações, como a correta indicação do material para que possa se evitar alguma intercorrência e também a possibilidade de descolagem e risco de fratura radicular decorrente de diferentes módulos de elasticidade ${ }^{7,8}$. Além das fraturas, infiltrações também são consideradas umas das falhas mais comuns que afetam esse tipo de restauração ${ }^{12}$.

Um estudo de Bindl e Mormann ${ }^{15}$ é citado por Carlos et al. $^{7}$ em que a falha encontrada em uma restauração das 19 cimentadas, ocorreu por cárie recorrente, ou seja, situações essas passíveis de ocorrer, mas evitáveis. Além disso, para um sucesso e longevidade da endocrown, são necessários um correto preparo do elemento dental, respeitando limites aceitáveis para um bom prognóstico, seleção da cerâmica mais adequada para o caso e escolha do material adesivo, uma vez que esse tipo de cimentação é essencial para casos de endocrown ${ }^{8}$.

\section{CASO CLÍNICO}

Paciente L.C.M.J de gênero masculino, com 55 anos de idade, compareceu a clínica da Faculdade de Odontologia de Araçatuba com necessidade de reabilitações protéticas nos arcos superior e inferior, sendo sua principal queixa questões estéticas e função prejudicadas (Figuras 1e 2).

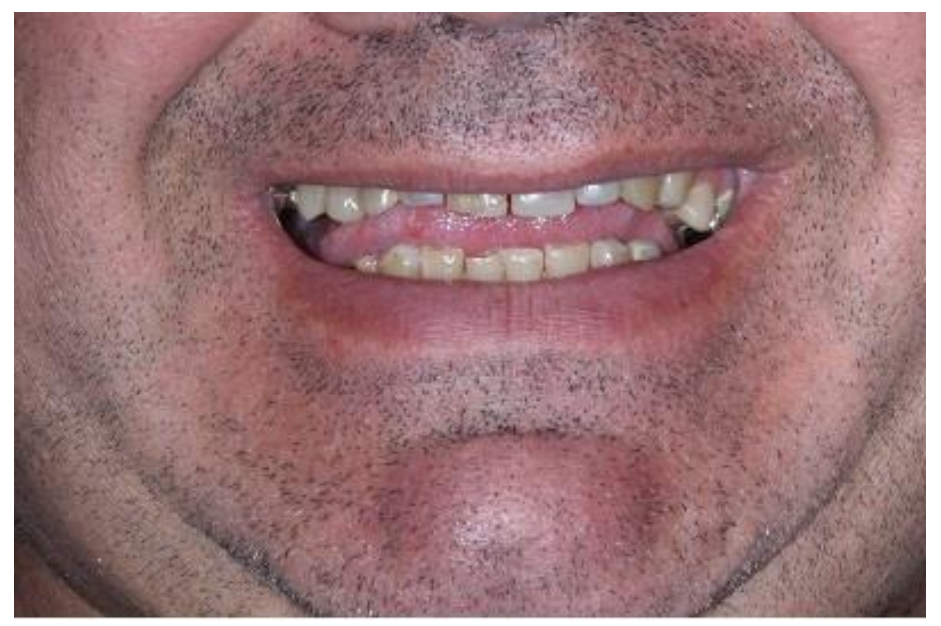

Figura 1: Vista frontal extrabucal do sorriso do paciente evidenciando alteração do plano oclusal da região anterior e posterior.

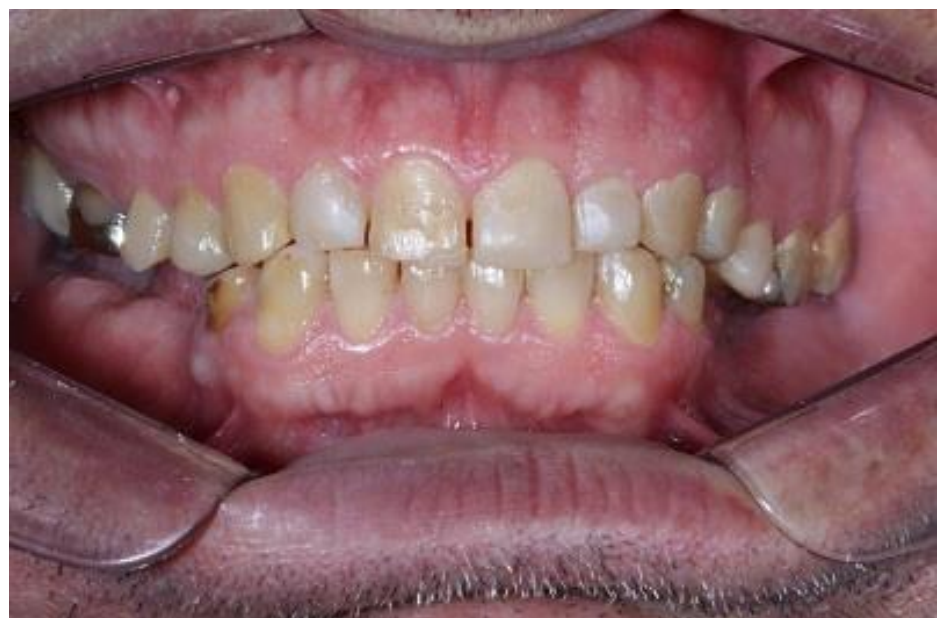

Figura 2: Vista intrabucal com o paciente em posição de máxima intercuspidação evidenciando dentes com alteração de cor, posição e formato, além de desnivelamento do plano de oclusão.

Através do exame clínico (anamnese e exame físico) foi detectado que o paciente apresentava parafunção, porém, com ausência de dor durante a palpação dos músculos, bem como não apresentava desgaste acentuado dos dentes. O paciente possuía no arco dentário superior os elementos 17 ao 27 , e no arco dentário inferior, do elemento 34 ao 44 
Além disso, o paciente apresentava extensas restaurações de resina composta com presença de infiltrações e manchamentos. Analisando a curvatura dos arcos foi observada, uma extrusão em bloco dos dentes posteriores maxilares (extrusão dentária, óssea e gengival do bloco) tanto do lado esquerdo, quanto do lado direito.

Diante da análise foi planejado e proposto ao paciente a reabilitação com coroas full veneer em todos os dentes do arco superior, com exceção do elemento 16 que devido a extensa destruição coronária foi proposta a realização de uma coroa endocrown.

Foi realizado ainda o recontorno gengival dos dentes posteriores para minimizar o desnível marginal provocado pela extrusão. Em relação ao arco inferior, foi planejado confecção de coroas full veneer nos elementos 34 ao 43, no elemento 44 foi realizado associação da coroa total com o pino de fibra de vidro, para posteriormente instalação de implantes na região de molares inferiores.

Assim, foi realizada a moldagem para obtenção dos modelos de estudo e realizada montagem no Articulador Semi Ajustável (ASA) com auxílio de arco facial para posicionamento do modelo superior e JIG para desprogramação da mandíbula permitindo a montagem do modelo inferior através do registro em relação central. Os modelos montados no ASA foram encaminhados ao laboratório para a realização do enceramento diagnóstico (Figuras 3 e 4 ).

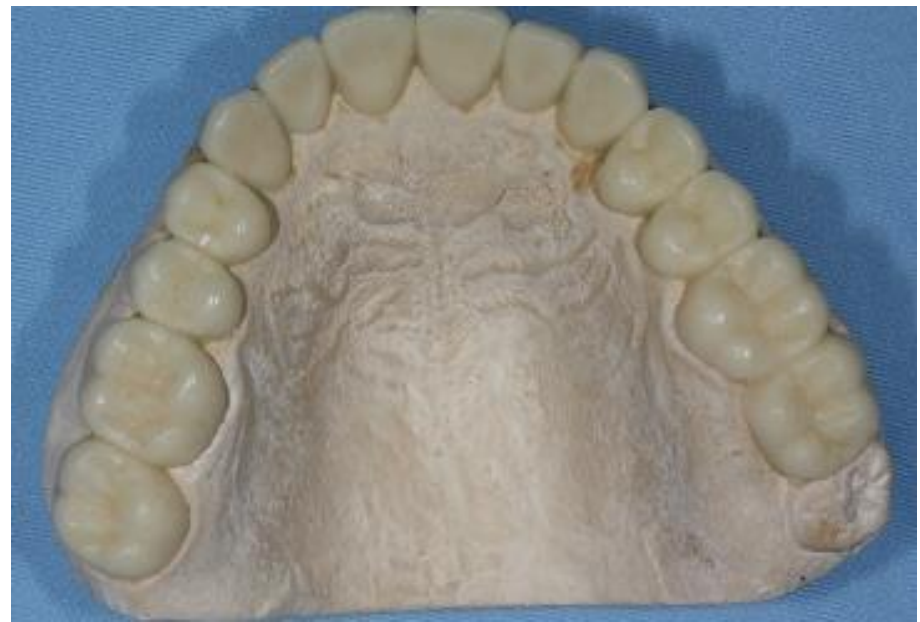

Figura 3: Vista oclusal do modelo superior já encerado após montagem em articulador semiajustável que restabeleceu a dimensão vertical de oclusão que estava alterada.

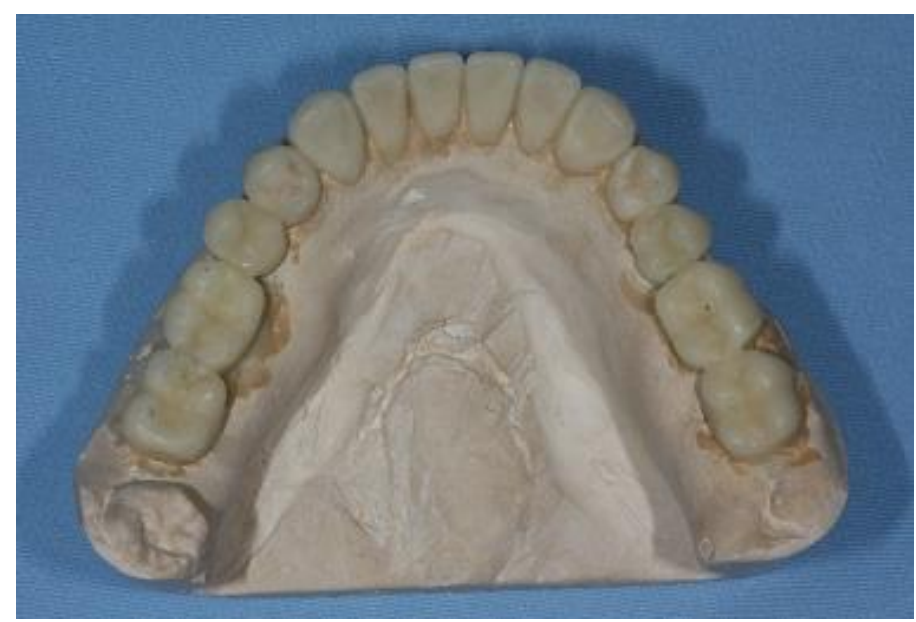

Figura 4: Vista oclusal do modelo inferior já encerado após montagem em articulador semiajustável que restabeleceu a dimensão vertical de oclusão que estava alterada.

Sobre os modelos de gesso superior e inferior encerados foram confeccionadas muralhas de silicone de condensação (Zetalabor - Zhermark) que servirão de guias para a realização do mock up (ensaio estético e funcional), assim como para orientar os desgastes e preparos dentários. Para realização do mock up sobre o guia foi colocado resina bisacrílica (Luxatemp - DMG) e levado em posição na boca do paciente até sua polimerização (4 minutos). Após a polimerização do material, o guia é removido da boca, e é obtido o mock up (Figura 5). O mock up permite mostrar ao paciente uma possível previsibilidade do tratamento, e serve para planejar possíveis alterações antes da confecção das restaurações finais.

Após aprovação do paciente, foram realizados os preparos então, com uma ponta diamantada 4138, deixando o término cervical em ombro arredondado, apropriado para peças protéticas metal free. No elemento 16 , foi realizado preparo com término cervical. Porém, também foi realizado preparo no interior da câmara pulpar após o selamento através de EDS e restauração com resina de baixa contração (Resina flow), permitindo a retenção macro mecânica para a técnica endocrown (Figuras 6 e 7).

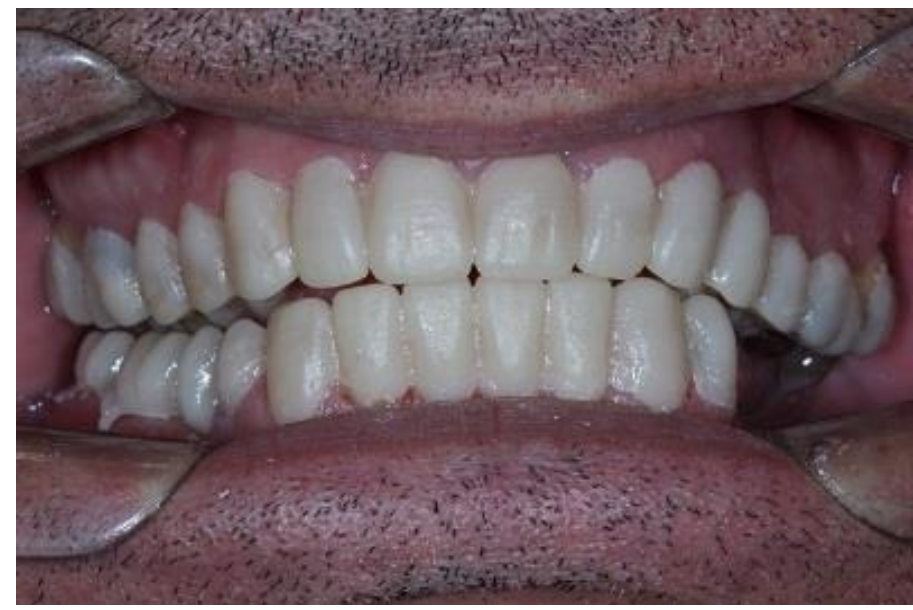

Figura 5: Vista intraoral após a realização do mock up superior inferior estando o paciente com a boca levemente entreaberta. Nota-se ainda, uma leve inversão dos planos de oclusão superior posterior do lado direito e esquerdo.

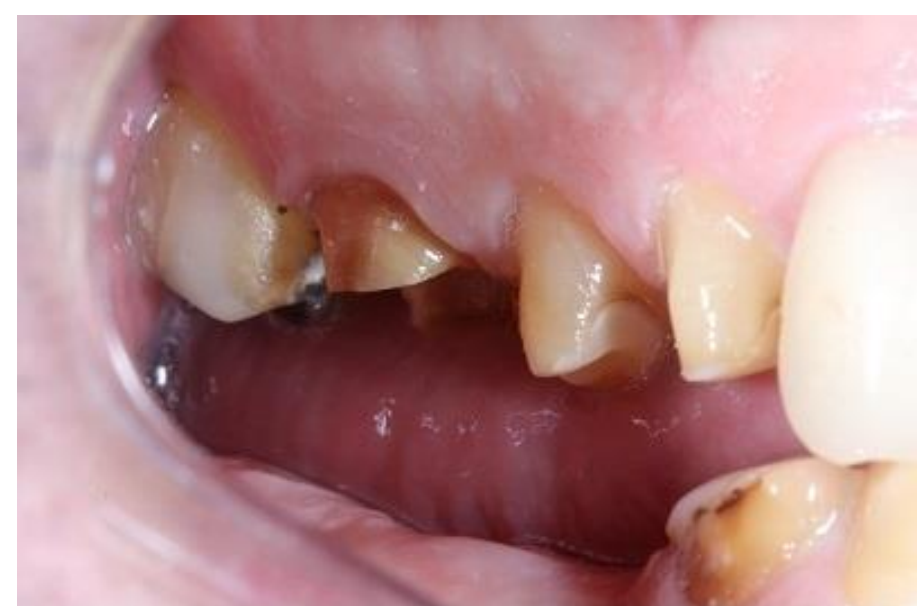

Figura 6: Vista vestibular do dente 16 com o devido preparo protético para receber a coroa endocrown.

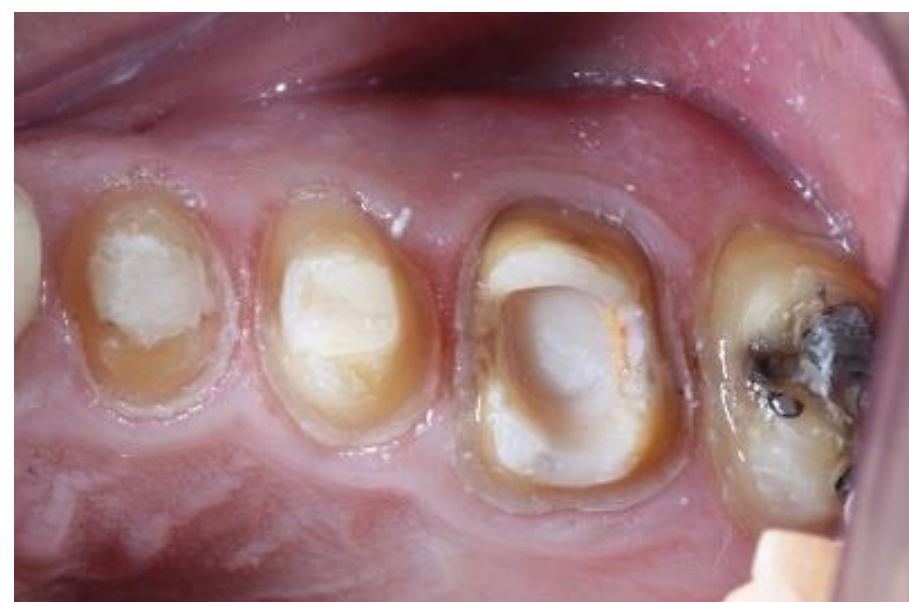

Figura 7: Vista oclusal do dente 16 com o devido preparo protético para receber a coroa endocrown.

Como observado nas Figuras 6 e 7, a coroa clínica curta do elemento 16 em comparação com os dentes adjacentes, associada a extrusão do mesmo elemento, favoreceu a indicação clássica para o uso da técnica endocrown, com desgastes mínimos na região de câmara pulpar para a retenção do material restaurador. Após a realização dos preparos (Figura 8), foi realizado o 
afastamento gengival pela técnica do duplo fio, utilizando o fio 000 (Ultradent) com hemostático (Hemostop - Dentsply) e sobre ele o fio 00 (Ultradent) sem hemostático, para moldagem através da técnica simultânea com silicone de adição (Honigum - DMG) auxiliada pelo uso da máquina de espatulação.

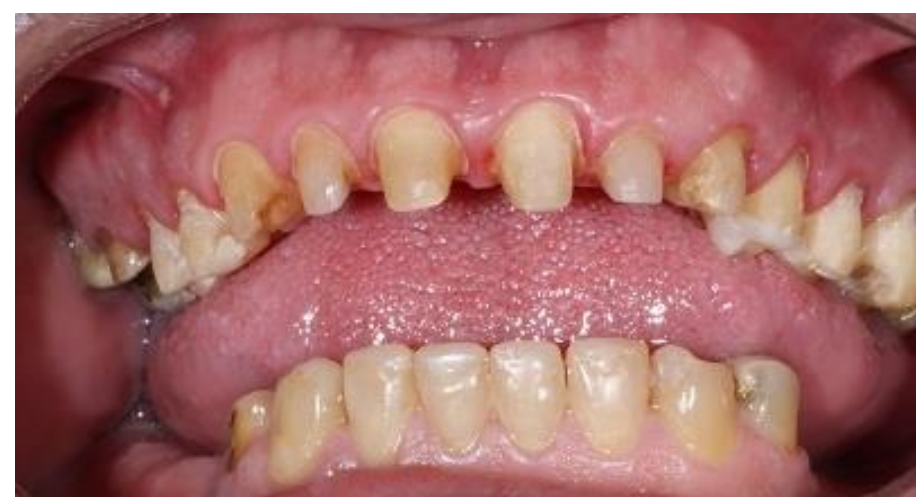

Figura 8: Vista vestibular dos dentes após realização dos preparos protéticos, já prontos para o procedimento de moldagem de trabalho.

No laboratório, os moldes foram vazados com gesso especial tipo IV duas vezes, sendo o primeiro vazamento reservado para ser troquelizado e o segundo vazamento para ser mantido íntegro (Figura 9 ).

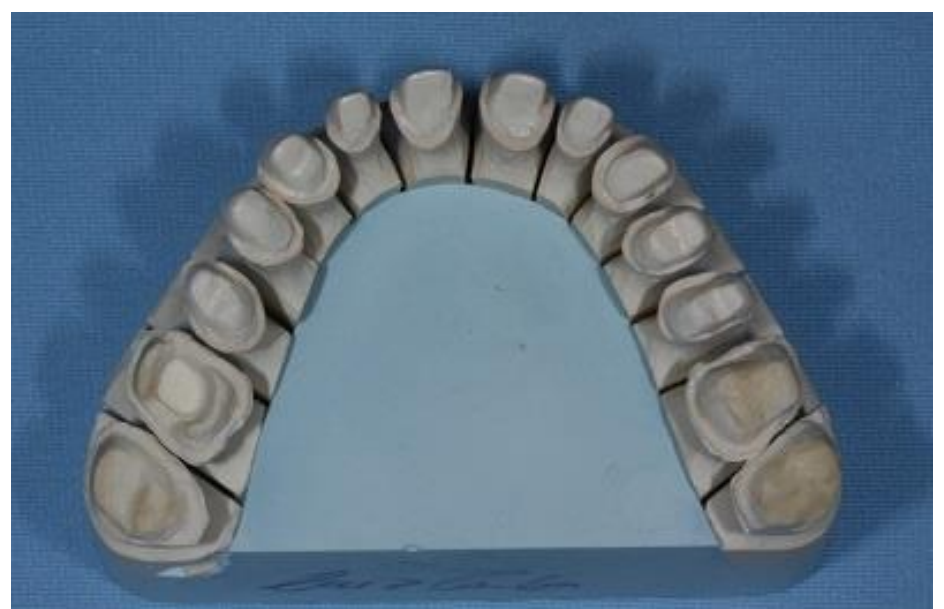

Figura 9: Vista oclusal do modelo superior troquelizado obtido após moldagem dos dentes preparados para confecção das próteses.

Após a etapa de moldagem, foi realizado registro oclusal utilizando material especifico (O-bite, DMG do Brasil) utilizando os provisórios como referência para a montagem. Foi feito a tomada de cor com registro fotográfico e provisório foi finalmente cimentado nos preparos utilizando cimento provisório a base de óxido de zinco sem eugenol (Figura 10).

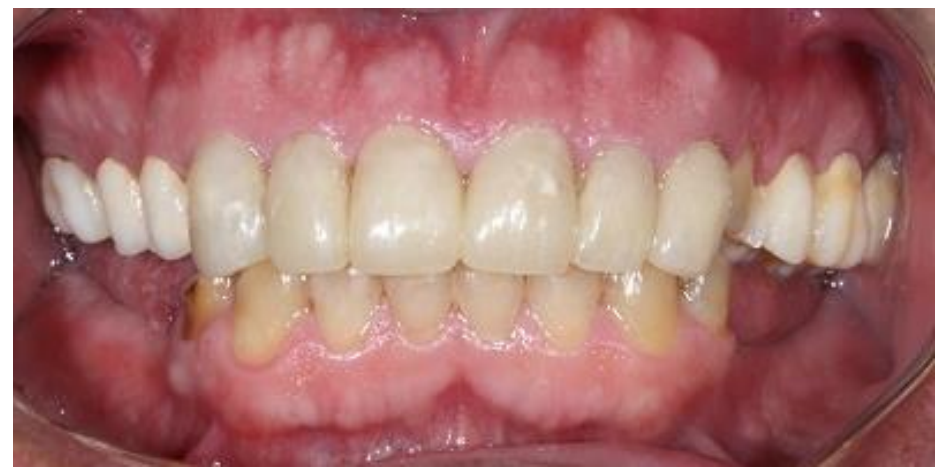

Figura 10: Vista frontal dos provisórios instalados após a moldagem dos dentes superiores preparados.

Para esse caso, o material cerâmico selecionado foi o IPS e.Max CAD-CAM - dissilicato de lítio monolítico, passando posteriormente pelo processo de maquiagem para que a peça ficasse com a cor mais próxima da cor do dente do paciente. Como observado, a coroa endocrown em monobloco favorece a resistência bem como a estética para o dente com coroa clínica curta (Figuras 11 e 12).

Após a confecção das peças protéticas, tanto a endocrown quanto as coroas totais, foram provadas nos modelos de gesso, superior e inferior (Figuras 13 e 14) para verificar presença de possíveis falhas ou distorções.

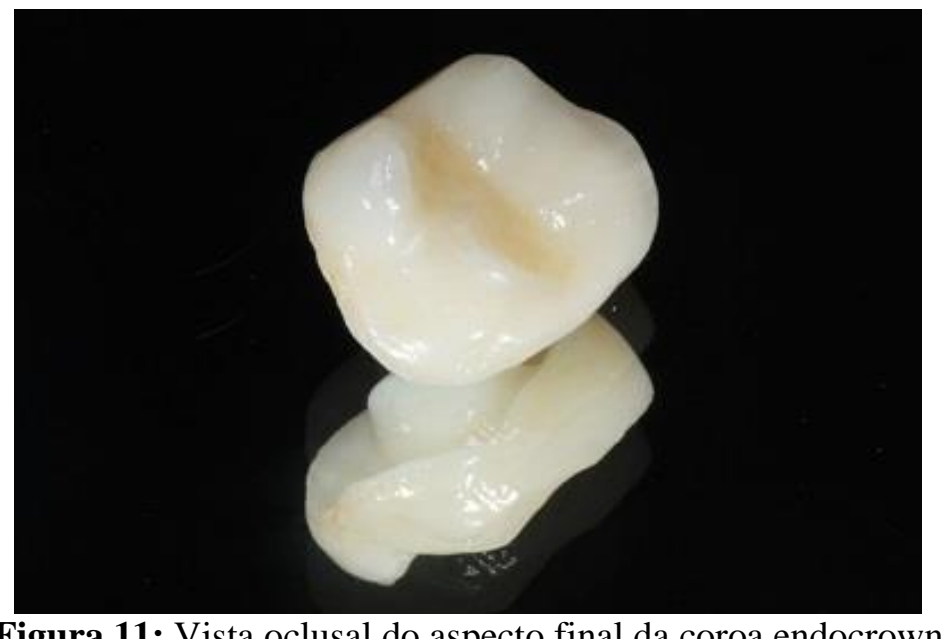

Figura 11: Vista oclusal do aspecto final da coroa endocrown

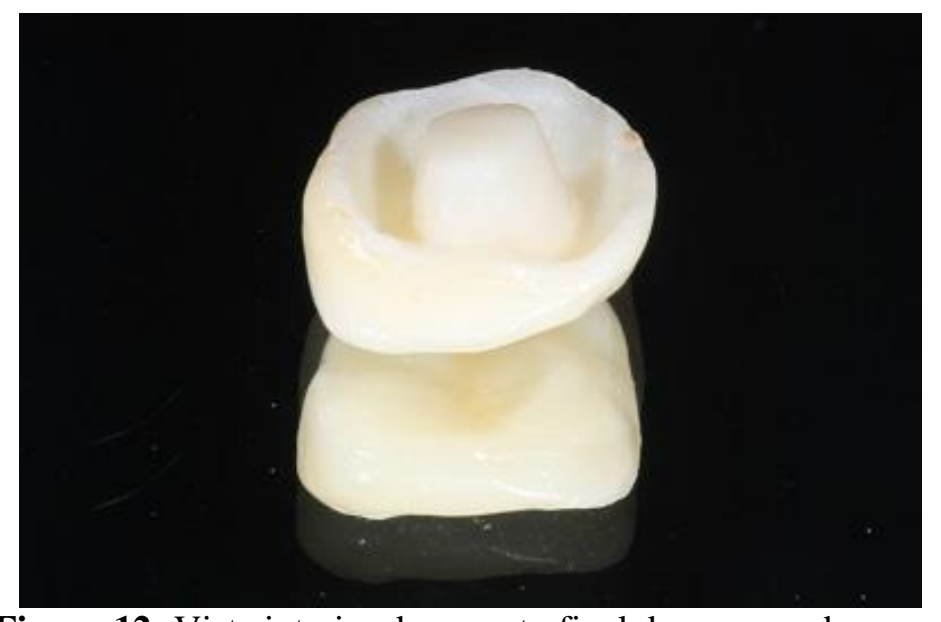

Figura 12: Vista interior do aspecto final da coroa endocrown

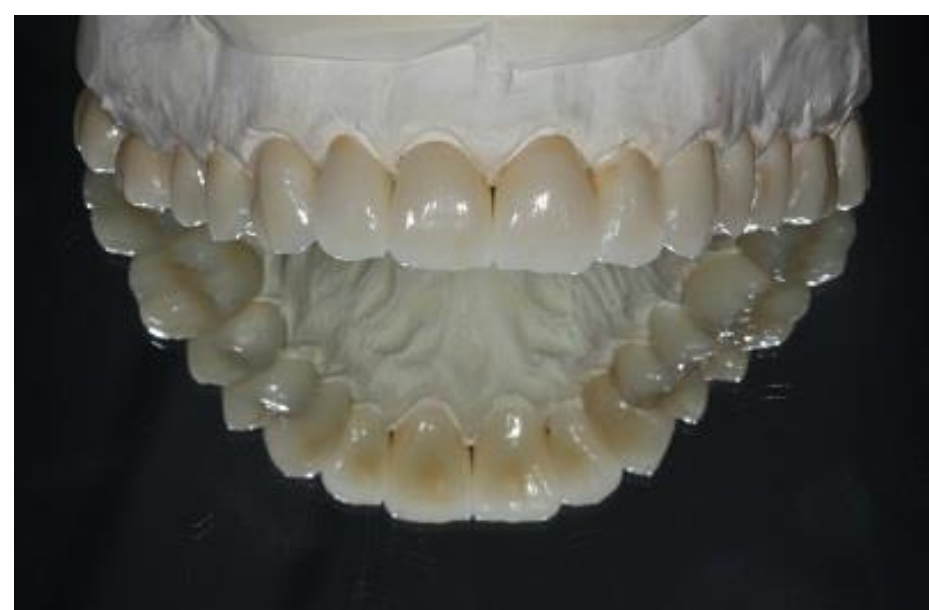

Figura 13: Peças protéticas confeccionadas e posicionadas sobre o modelo de gesso superior.

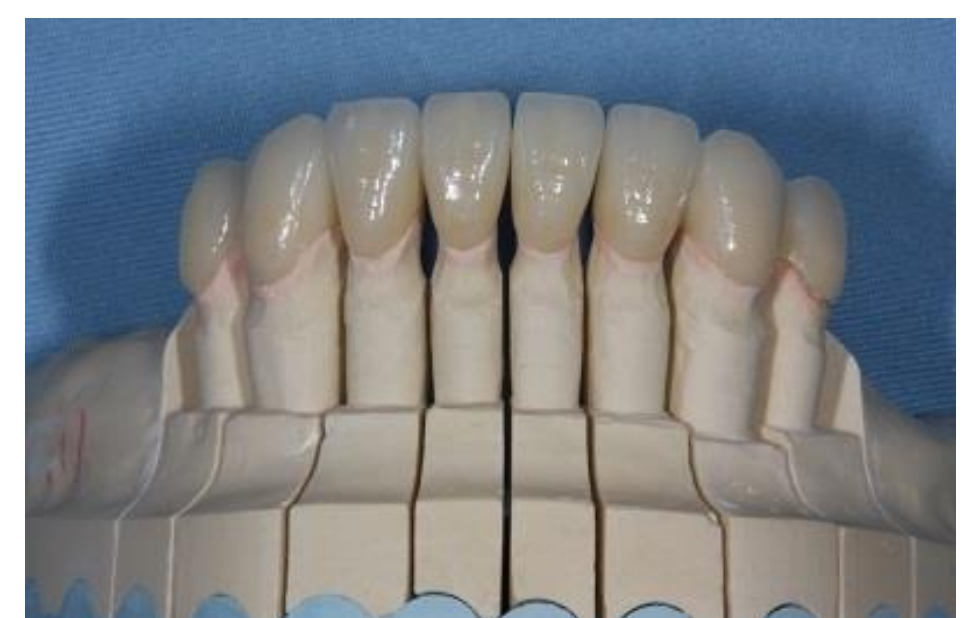

Figura 14: Peças protéticas confeccionadas e posicionadas sobre o modelo de gesso inferior.

Após verificação das peças protéticas no modelo, foi avaliado sua adaptação marginal e contatos proximais diretamente nos dentes preparados. Aprovado a checagem, as peças receberam preparo para cimentação adesiva seguido do preparo dos dentes, como mostra nos tópicos em sequência a seguir:

* Condicionamento da peça:

- Ácido fluorídrico a 10\% por 20 segundos; 
- Lavagem abundante em água corrente e secagem;

- Limpeza com ácido fosfórico a 35\% ativamente durante 1 minuto;

- Lavagem abundante em água corrente e secagem;

- Aplicação do silano por 1 minuto e secagem dessas peças a 100 graus Celsius por 1 minuto com auxílio de um secador de cabelo.

* Condicionamento dos elementos dentários:

- Profilaxia com pedra pomes e água;

- Após o enxágüe, foi aplicado o ácido fosfórico a $35 \%$ por 15 segundos por ser em dentina a aplicação;

- Lavagem com água corrente e secagem ligeiramente para que as fibras colágenas fossem preservadas.

- Aplicação do adesivo dual (Excite - Ivoclar).

Sendo respeitados todos esses passos, as peças estavam prontas para serem cimentadas. Foi realizado isolamento relativo (Optpragate - Ivoclar) e para a cimentação adesiva foi utilizado o Cimento Variolink $\mathrm{N}$ (Ivoclar Vivadent) na cor transparente (Figura 15).

Devido ao hábito parafuncional previamente diagnosticado no paciente, foi realizada a confecção de uma placa miorrelaxante como tentativa de minimizar os efeitos deletérios sobre as novas peças cerâmicas, e consequentemente a reabilitação final (Figuras 16 e 17).

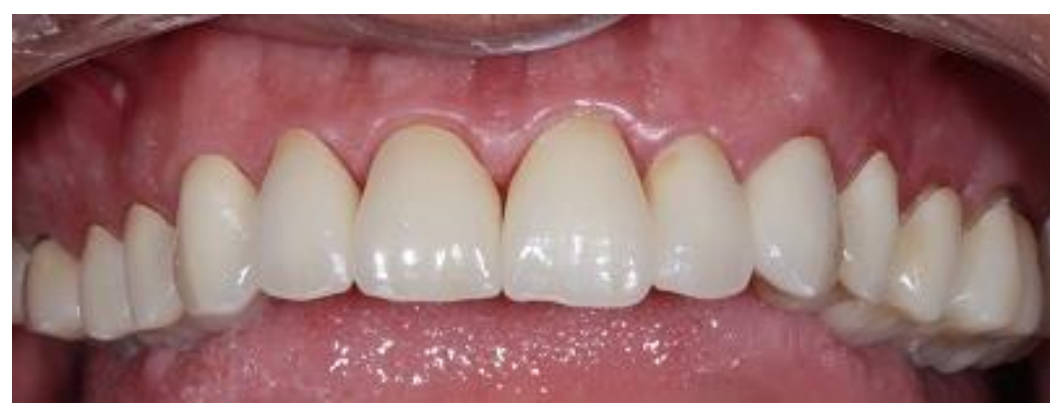

Figura 15: Peças protéticas superiores cimentadas nos dentes dos pacientes.

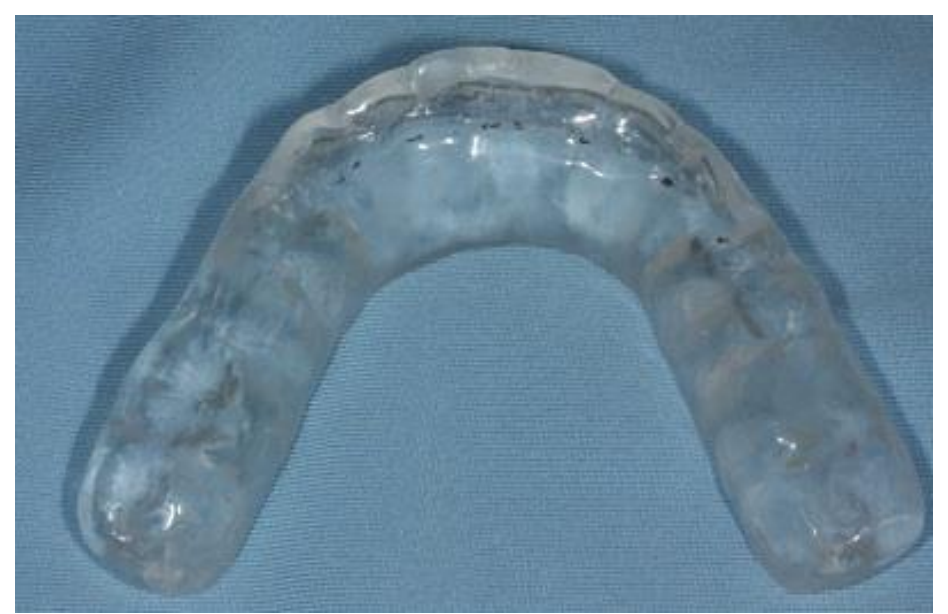

Figura 16: Aspecto oclusal da placa miorrelaxante confeccionada para instalação no arco superior.

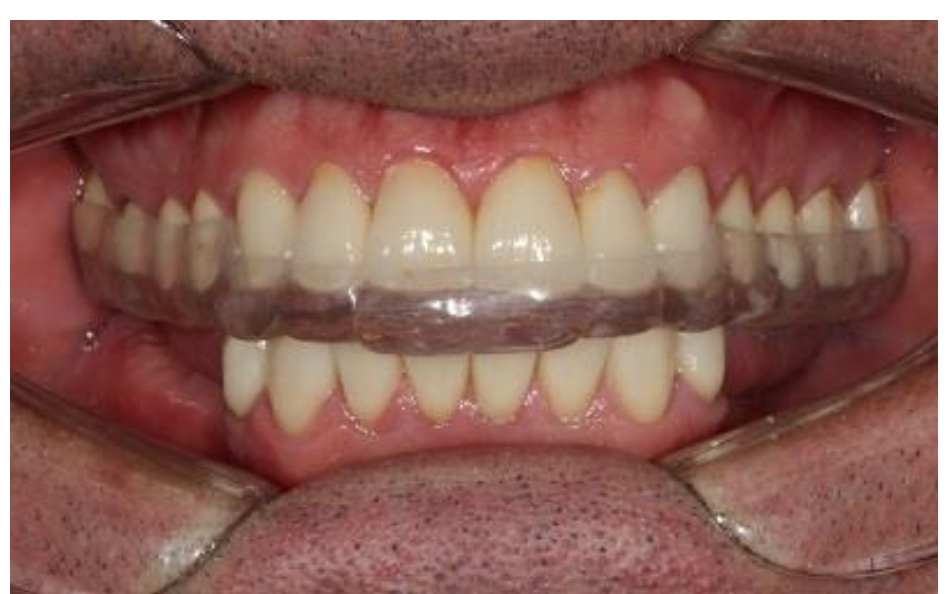

Figura 17: Aspecto vestibular da placa miorrelaxante instalada no arco superior.

Após cimentação, foram marcadas consultas de retorno após 1 e 6 meses, verificando os contatos oclusais, bem como o contorno gengival, sendo verificado um bom resultado estético, funcional e com saúde periodontal Orienta-se que os retornos continuem semestralmente para um acompanhamento minucioso e ajuste na placa estabilizadora.

\section{DISCUSSÃO}

O caso clínico apresentado não só evidenciou, como foi ao encontro da literatura em relação à indicação da técnica endocrown para dentes posteriores com altura coronária comprometida, principalmente em molares, contribuindo para um favorável desempenho satisfatório em relação às cargas fisiológicas, com canais radiculares calcificados ou raízes muito finas, comprimento de coroa clínica inadequado $^{6-10}$, o que dificultaria a realização de um núcleo metálico fundido, bem como a confecção de uma coroa metaloceramica, devido à pouca espessura para o metal e material cerâmico.

Quando o elemento dentário não apresenta as características citadas acima, o uso de coroas totais convencionais associadas ou não ao uso do núcleo fundido ou pino pré-fabricado de fibra de vidro associado às restaurações indiretas são tratamentos de escolha para reabilitação. As grandes limitações nesses casos seriam justamente o maior desgaste de estrutura dentária realizado, pois se faz necessário a utilização do conduto radicular, além dos riscos acidentais de trepanação, decorrente da desobturação dos $2 / 3$ do canal radicular para que a retenção seja efetiva. Há na literatura incidências de raízes de molares que possuem alterações anatômicas ${ }^{8,9,12}$. Nesses casos também é aumentada a complexidade desse tratamento, pois o manejo necessita de ainda mais cuidados para evitar esses tipos de acidentes.

Esse procedimento que visa principalmente à preservação dental, garantindo resultados estéticos mais eficientes, assim como um tratamento mais rápido no consultório e menos oneroso ao paciente. Além disso, notase uma resistência à fratura significativa ${ }^{7,8,12}$ notadamente para molares, já em pré-molares os resultados ainda são controversos devido à susceptibilidade as forças transversais durante a mastigação ${ }^{8,16}$. Muito disso pode estar relacionado com a câmara pulpar mais ampla permitindo maior área do material restaurador, e assim menor risco de complicações relacionadas a fratura do material ${ }^{8}$. Além disso, os prémolares apresentam uma cúspide mais alta em relação aos molares e isso pode ocasionar maiores forças exercidas nessa região devido ao movimento de alavanca comprometendo a resistência do material ${ }^{9}$.

Pode ser observada inúmeras vantagens para o uso da técnica endocrown, como a estética e função são estabelecidas permitindo maior conservação de tecido dentinário e esmalte periférico em comparação a coroas totais convencionais, pois é eliminada a necessidade do uso de retenção intracanal por ser uma técnica adesiva. A preservação de tecido promove maior estabilidade marginal, e isso se dá graças à evolução dos materiais adesivos que nos permitem trabalhar com menor desgaste dentário e mesmo assim nos asseguram a retenção necessária desejada. Outro ponto importante seria de que as margens da restauração são mantidas fora do periodonto, sendo assim benéfico para conservação da higiene oral e saúde periodontal. Mesmo assim, como já foi dito, a instrução ao paciente em relação a adequada higiene bucal é de suma importância para que auxilie ainda mais no sucesso do tratamento. Em relação aos passos técnicos, os mesmos são diminuídos em comparação a quando é realizada uma reabilitação com núcleo ou pino com coroas totais, portanto, menos sessões clínicas são 
requisitadas, com benefício mútuo para o profissional e paciente. Em relação à confecção da peça protética, com a evolução dos sistemas cerâmicos e dos sistemas de confecção, a fresagem é mais precisa, com formato personalizado, adaptação da superfície interior da restauração e a replicação da morfologia oclusal melhores, as imprecisões e contaminação cruzada são mínimas, evita contração de polimerização por ser uma restauração indireta e se tem melhor adesão e satisfação por parte do paciente.

Entretanto, a técnica endocrown apresenta limitações que podem ser minimizadas com a indicação realizada de forma correta. Como por exemplo, deve-se essa técnica pode não ser indicada para situações em que não é possível assegura a adesão do material restaurador a estrutura dentária $^{8,9,12}$. Esse comprometimento é causado em situações clínicas nas quais a câmara pulpar apresenta profundidade inferior a 3 milímetros, ou quando a margem cervical apresenta largura inferior a 2 milímetros na maior parte da circunferência, prejudicando a retenção e também em relação ao material de escolha para que seja confeccionada a peça.

Em relação ao material utilizado, deve-se evitar algum material com uma diferença muito grande entre o módulo de elasticidade em comparação com a dentina. Deve ser considerado qual o dente será reabilitado para não ter intercorrências devido à resistência flexural da peça. No caso clínico apresentado foi escolhido o Dissilicato de Lítio Monolítico que possui resistência flexural de $400 \mathrm{MPa}$ (Mega Pascal), que é suficiente para aguentar as cargas de forças de molares, além de que esse material tem uma estética muito satisfatória devido a sua composição que possui uma matriz vítrea, sendo classificada como uma cerâmica ácido-sensível. A Zirconia é uma cerâmica que também pode ser indicada, possui uma resistência flexural que varia de 900 a $1.200 \mathrm{MPa}$, porém devido a ser classificada como uma cerâmica ácido-resistente, ou seja, sem essa matriz vítrea, sua estética não favorável, sendo uma cerâmica extremamente branca e opaca.

Outro ponto de extrema importância, além da escolha do material é o processo de cimentação da endocrown. Para que seja conferida a retenção micro-mecânica deve-se lançar mão de um material cimentante adesivo, sendo compatível com a cerâmica utilizada. No caso clínico apresentado o cimento resinoso utilizado foi o Variolink N (Ivoclar), que confere um sistema dual de polimerização, tanto fotoativado, quanto quimicamente ativado. Essa característica é importante, pois, devido a retenção macro mecânica ser no interior da câmara pulpar, ao utilizar o fotopolimerizador, a luz não consegue atravessar totalmente a própria cerâmica para chegar nessa região, promovendo uma deficiência na cimentação. Dessa forma o sistema dual, dribla essa dificuldade, promovendo uma polimerização química que independe de luz para essa região mais dificultosa e a polimerização através da foto ativação auxilia nesse processo, agindo principalmente na linha de cimentação.

A literatura aponta que além de fraturas, as infiltrações são umas das causas mais comuns que afetam esse tipo de restauração, fator esse que pode ser evitado com cuidados com a técnica no ato de cimentação da peça, controles periódicos desse paciente e a colaboração do mesmo, sendo então necessário instruir esse paciente e fazer com que ele entenda a importância da higiene bucal ${ }^{12}$.

Analisando todos os aspectos apontados, é importante salientar que para um caso clínico obter sucesso a longo prazo utilizando endocrown, seria interessante ter a atenção em alguns critérios como o correto preparo dental, seleção da cerâmica a ser utilizada no caso e sua confecção, afim de evitar possíveis falhas ou distorções por preparo manuseio incorreto do material protético, correta indicação do uso da técnica e material cimentante adequado e há a necessidade de mais estudos a respeito da mesma para comprovar a efetividade do uso e explorar a possibilidade do sucesso em dentes como pré-molares.

\section{CONSIDERACÕES FINAIS}

A revisão realizada permite observar que a utilização de coroas endocrown pode ser considerada um tratamento favorável para dentes com extensa destruição coronária e pequeno espaço interoclusal, garantindo elevada resistência a fratura. Entretanto, a longevidade do tratamento está relacionada com a correta indicação das cerâmicas e cimentos utilizados, além da correta adequação do preparo.

\section{REFERÊNCIAS}

1. Boschian Pest L, Guidotti S, Pietrabissa R, Gagliani M. Stress distribution in a post-restored tooth using the three-dimensional finite element method. J Oral Rehabil. 2006; 33(9):690-7.

2. Dietschi D, Duc O, Krejci I, Sadan A. Biomechanical considerations for the restoration of endodontically treated teeth: a systematic review of the literature-Part 1. Composition and micro- and macrostructure alterations. Quintessence Int. 2008; 39(2):117-29.

3. Moro M, Agostinho AM, Matsumoto W. Núcleos metálicos fundidos x pinos pré-fabricados. PCL 2005; 7(36):167-72.

4. Lassila LV, Tanner J, Le Bell AM, Narva K, Vallittu PK. Flexural properties of fiber reinforced root canal posts. Dent Mater. 2004; 20(1):29-36.

5. Mörmann WH, Bindl A, Lüthy H, Rathke A. Effects of preparation and luting system on all-ceramic computergenerated crowns. Int J Prosthodont. 1998; 11(4):333-9.

6. Rocca GT, Rizcalla N, Krejci I. Fiber-reinforced resin coating for endocrown preparations: a technical report. Oper Dent. 2013; 38(3):242-8.

7. Carlos RB, Nainan MT, Pradhan S, Sharma R, Benjamin S, Rose R. Restoration of endodontically treated molars using all ceramic endocrowns. Case Rep Dent. 2013; 2013:210763.

8. Biacchi GR, Mello B, Basting RT. The endocrown: an alternative approach for restoring extensively damaged molars. J Esthet Restor Dent. 2013; 25(6):383-90.

9. Chang CY, Kuo JS, Lin YS, Chang YH. Fracture resistance and failure modes of CEREC endo-crowns and conventional post and core-supported CEREC crowns. J Dent Sci 2009; 4(3):110-7.

10. Borges Junior HE, Sabio S, Bender KRF, Costa YM, Mondelli J. Endocrown - avaliação da resistência dos cimentos dentários. Rev Odontol Araçatuba. 2013; 34(2):23-6.

11. Hussain SK, Mcdonald A, Moles DR. In vitro study investigating the mass of tooth structure removed following endodontic and restorative procedures. J Prosthet Dent. 2007; 98(4):260-9.

12. Dejak B, Młotkowski A. 3D-Finite element analysis of molars restored with endocrowns and posts during masticatory simulation. Dent Mater. 2013; 29(12):e309-17.

13. Edelhoff D, Sorensen JA. Tooth structure removal associated with various preparation designs for posterior teeth. Int J Periodontics Restorative Dent. 2002; 22(3):241-9. 
14. Goldberg PV, Higginbottom FL, Wilson TG. Periodontal considerations in restorative and implant therapy. Periodontol 2000. 2001;25:100-9.

15. Bindl A, Mörmann WH. Clinical evaluation of adhesively placed Cerec endo-crowns after 2 years-preliminary results. J Adhes Dent. 1999; 1(3):255-65.

16. Otto T. Computer-aided direct all-ceramic crowns: preliminary 1-year results of a prospective clinical study. Int J Periodontics Restorative Dent. 2004; 24(5):446-55.

\section{CONFLITO DE INTERESSES}

Os autores declaram não haver conflitos de interesse.

\section{AUTOR PARA CORRESPONDÊNCIA}

Adriana Cristina Zavanelli

zavanelliac@foa.unesp.br

Submetido em 06/06/2017

Aceito em 05/07/2017 